have implications on the development of assessment and management pathways for this under-recognised patient cohort.

\section{SINGLE-CELL RNA SEQUENCING REVEALS CARDIAC CELL-SPECIFIC TRANSCRIPTOMIC CHANGES IN DILATED CARDIOMYOPATHY}

${ }^{1} \mathrm{~A}$ Russell-Hallinan*, ${ }^{10}$ Cappa, ${ }^{1} \mathrm{~L}$ Kerrigan, ${ }^{2} \mathrm{C}$ Moravec, ${ }^{2} \mathrm{P}$ Collier, ${ }^{1} \mathrm{D}$ Simpson, ${ }^{1} \mathrm{C}$ Watson. 'Wellcome-Wolfson Institute for Experimental Medicine, Queens University Belfast, UK; ${ }^{2}$ Department of Cardiovascular and Metabolic Sciences, Lerner Research Institute, Cleveland Clinic, Ohio, USA

10.1136/heartjn|-2021-ICS.16

\section{NOT AVAILABLE FOR PUBLICATION}

\section{THE NATURAL HISTORY AND STAGING OF PRE-CLNICAL HEART FAILURE}

${ }^{1} \mathrm{~A}$ Moore, ${ }^{1} \mathrm{~A}$ Brennan, ${ }^{2} \mathrm{M}$ Ledwidge, ${ }^{1} \mathrm{~K}$ McDonald. ${ }^{1}$ St Vincent's University Hospital, Dublin, Ireland: ${ }^{2}$ Heartbeat Trust, Dublin, Ireland

\subsection{6/heartjnl-2021-ICS.17}

Introduction Heart failure (HF) is growing global epidemic. Given the high morbidity and mortality associated with HF, and the impact it has on an already stretched health care system, its effective management is a public health priority. Prevention is a critical component of this strategy and this is dependent on a more complete understanding of the natural history of the condition, especially its preclinical precursors.

Methods St Vincent's University Hospital offers a HF Prevention service (STOP-HF) targeted towards patients in its catchment area that have risk factors for HF. We retrospectively analysed the serial echocardiographic and natriuretic peptide data of 1,425 of these patients who have had at least two visits. Stage A was defined as no previous diagnosis of $\mathrm{HF}$ and a normal echocardiogram with one or more of the following: hypertension, hypercholesterolemia, obesity, vascular disease, diabetes mellitus, arrhythmia requiring therapy or significant valvular disease. Stage B, a cohort at higher risk of development of heart failure, was defined as no previous diagnosis of $\mathrm{HF}$ and evidence of a structural or functional abnormality on echocardiography including: ejection fraction $<50 \%$, diastolic dysfunction, left ventricular hypertrophy, valvular disease of at least moderate severity, an enlarged left ventricle or an abnormal LAVI. Demographics, comorbidities, medication use and biochemical data were also analysed from each visit.

Results A population of 1425 was analysed. On average, visit 2 was completed 4.8 years after visit 1 . The average age at visit 1 was $64 y$ rs with females accounting for $46 \%(n=649)$. At visit $1,72 \%(n=1022)$ of the population were classified as Stage A and $28 \%$ Stage B. The average BNP of a Stage A patient was $28 \mathrm{pg} / \mathrm{ml}$ while the average BNP of a Stage B patient was $64 \mathrm{pg} / \mathrm{ml}$. At visit 2, 60\% $(\mathrm{n}=858)$ of patients were classified as Stage A with $40 \%$ Stage B. At visit 2, the average BNP of a Stage A patient was $35 \mathrm{pg} / \mathrm{ml}$ while the average BNP of a Stage B patient was $141 \mathrm{pg} / \mathrm{ml}$. In terms of progression, $53 \%$ of patients remained in Stage A, 18\% progressed to Stage B, 21\% remained in Stage B and 7\% had regressed from Stage B to Stage A. The most prevalent manifestation of progression was an increase in LAVI while the notable change in patients demonstrating regression from Stage
B to Stage A was a reduction in LVH. In terms of changes in BNP between the two visits, those who remained in Stage A had an average BNP increase of $10 \mathrm{pg} / \mathrm{ml}$ from visit 1 to visit 2. Similarly, those who regressed from Stage B to Stage A had an average increase in BNP of $22 \mathrm{pg} / \mathrm{ml}$, whereas those that progressed from Stage A to Stage B had an average increase in BNP of $68 \mathrm{pg} / \mathrm{ml}$.

Summary This natural history study of a large sample of patients at risk for the development of heart failure demonstrates a significant proportion of patient with Stage B and furthermore a concerning progression rate of progression from Stage A to Stage B. Our data also identify a change in NP as a useful clinical biomarker of Stage B and risk of progression. It is hoped that this initial study will form as a baseline for further analysis and help guide screening and prevention strategies in the future

\section{MANAGEMENT AND OUTCOMES OF PATIENTS WITH LEFT ATRIAL APPENDAGE THROMBUS PRIOR TO PERCUTANEOUS CLOSURE. LAPTOP REGISTRY}

A McInerney, L Maroquin, G Tirado-Conte, P Salinas-Sanguino, L Nombela-Franco. Hospital Clínico San Carlos, Spain

10.1136/heartjnl-2021-ICS.18

NOT AVAILABLE FOR PUBLICATION

\section{YEAR RESULTS OF THE CARDIOLOGY TRAINEE FEEDBACK PROJECT}

N Fitzpatrick, BF McAdam, J Crowley, B McNeill, R Murphy, B Dalton. Irish Board for Training in Cardiovascular Medicine, Dublin, Ireland

\subsection{6/heartjnl-2021-ICS.19}

Background The Higher Specialist Training (HST) Scheme is run by the Royal College of Physicians (RCPI) overseen by the Irish Board for Training in Cardiovascular Medicine (IBTCM). The stated aim of the scheme is to provide doctors upon completion, with the necessary skills and knowledge to practice competently, professionally and independently as cardiology specialists. In order to inform dialogue surrounding improvements to the training scheme, those enrolled have been surveyed annually over the past 4 years to gage their views regarding the following domains - trainer/trainee interaction, access to training, procedural training, service commitments and training, research and audit, training program structure, gender balance, future career planning and location, quality of life and in the past year the impact of the Covid19 pandemic on training.

Methods For the past 4 years, the second author surveyed trainees in training years 1-4 through the medium of an online questionnaire. Trainees were asked to respond to a range of questions pertaining to the domains of interest listed above, predominantly indicating their level of agreement with a statement in the format of a 5 point Likert scale.

Results The response rate to the survey was excellent and averaged at $65 \%$ over the four years. Individual years ranged from $52 \%$ to a high of $82 \%$. Even in the year with the lowest response $(52 \%)$ a significant proportion of the trainees were represented. Overall trainees are happy with the training scheme with $88 \%$ saying they would recommend the 